\title{
A Systematic Investigation on Barriers and Critical Success Factors for Clinical Information Systems in Integrated Care Settings
}

\author{
A. Hoerbst, M. Schweitzer \\ Research Division eHealth and Telemedicine, UMIT - University for Health Sciences, Medical \\ Informatics, and Technology, Hall in Tirol, Austria
}

\begin{abstract}
Summary
Objectives: Clinical Information Systems (CIS) have ever since the introduction of information technology in healthcare played an important role to support healthcare professionals and the process of treatment. With the rise of the concept of integrated care organizational borders, the sole focus on data aggregation or healthcare professionals as users disappear more and more. The manuscript discusses the concept of CISs and investigates critical success factors for CISs in the context of integrated care and in the course of time.

Methods: In order to identify critical success factors and barriers for CISS a systematic literature review was conducted based on the results from PubMed and Cochrane, using MaxQDA. Search results were thereby limited to reviews or meta-analysis.

Results: We have found 1919 references of which 40 met the inclusion criteria. The analysis of the manuscripts resulted in a comprehensive list of success factors and barriers related to CISs in integrated care settings. Most barriers were user-related whereas for the success factors an even distribution of organizational, technical and user-related factors was observed. The vast majority of publications was focused on healthcare professionals. Conclusion: It is important to incorporate experiences made/ collected over time, as the problems encountered seem to remain almost unvaried. In order to support further systematic investigations on the topic it is necessary to rethink existing concepts and definitions to realign them with the ideas of integrated care.
\end{abstract}

\section{Keywords}

Clinical information system, success factor, barrier, integrated care

Yearb Med Inform 2015;10:79-89

http://dx.doi.org/10.15265//Y-2015-018

Published online August 13, 2015

\section{Introduction}

Clinical Information Systems (CIS) have ever since the introduction of information technology in healthcare played an important role to support healthcare professionals and increase overall efficiency in the process of treatment. A study of the Mid-sixties indicated that around one quarter of the labor cost in hospitals was associated with information processing [1] so clinical information systems along with the more holistic hospital information systems were meeting an urgent demand in healthcare to reduce costs for information processing. Although CISs were not the first computer supported systems, they were amongst the earliest. Hospital executives often favored the introduction of administrative systems, especially billing systems as the reimbursement mechanisms were mainly based on a fee-for-service principle [2].

First prototype implementations of CISs date back to the early sixties such as the HELP system [3] from the Latter-Day Saints Hospital in Salt Lake City or the Oncology Clinical Information System [4] at the Johns Hopkins University.

An early definition from the eighties defined Clinical Information Systems (CIS) as: computer supported applications with a relatively large and long-term database containing clinical data that are used to assist in the management of patient care [5].

The definition highlights the major attributes of the first clinical information systems as well as puts them in relation to the concept of hospital information systems as their clinical subsystems. The focus at that time was clearly towards the basic collection and integration of data within hospitals in an ambulatory and inpatient care-setting so that data access for healthcare professionals could be provided in a more uniform and centralized way.

Another major driver for clinical information systems in the early days was the rising automation and availability of technology such as laboratory systems, which offered first interfaces for data exchange and extraction. Interestingly, a review from the mid-eighties already proclaimed that clinical information systems were to be regarded as a mature technology, which surprisingly is not used comprehensively in healthcare [5].

While the role and expected functionality - although often not completely available at that time - seemed to be obvious for the first clinical information systems, different technological, economical or even socio-demographic developments have changed the view on CISs substantially over the last decades.

The movement towards managed care in the US at the beginning of the nineties and the fight against cost inflation in healthcare is a good example to illustrate the changing requirements with regard to CISs over time [2]. These macro-economic developments have led to the establishment of new or the extension of existing paradigms in healthcare. In order to be able to meet the requirements imposed by e.g. integrated care scenarios, specialization, patient empowerment or disease prevention resulting from the changed and extended structures of healthcare provision (see e.g. [6]), it is necessary that health information technology adapts constantly and accordingly.

The number of factors that have shaped CISs over time is diverse and their discussion 
would go beyond the scope of this article. Therefore, three fundamental developments and their importance are highlighted: the proliferation of the concept of Integrated Care, Electronic Health Records and the call for the empowerment of patients.

\subsection{Integrated Care}

As has already been introduced in the previous section the concept of managed care marked an important step in healthcare, which was specific to the US but has inspired many different developments all over the world [7]. In the last decades, integrated care became the term that is most often used to summarize this paradigmatic shift in healthcare on a global basis.

Although often applied, Integrated Care is a term, which is still very vague. This is primarily due to the facts that there are many differences in the organization of (health) care across nations, that it is used as an umbrella term and that integration can be tackled from different levels or perspectives e.g. functional, organizational, professional, clinical (see e.g. $[7,8]$ ). Indeed the most common taxonomies distinguish by type, degree, process and breadth of integration [9]. In [7] major drivers such as service fragmentation and redundancies; continuity and coordination problems; inefficient use of resources; missing consumer centeredness; suboptimal outcomes and chronic illness for integrated care are given. Similar factors were identified by [10].

From a patient perspective, integrated care should amongst others support easy access to and navigation within healthcare as well as seamlessly integrate care; from a provider perspective the coordination of tasks, services and care across professional and organizational boundaries is important $[7,11]$. Several recent and older publications have also emphasized the importance of (clinical) information systems [10, 12, 13] as a supportive technology in order to enable integrated care scenarios.

If one deliberates the concept of integrated care and combines it with the fact that information technology is a prerequisite, it is obvious that also CISs face major changes that are subject to the changed environment in healthcare. To successfully meet these demands it is necessary to extend the scope of CISs beyond (local) data integration, health professionals and organizational boundaries.

\subsection{The Role of Electronic Health Records}

The concept of trans-institutional patient-centered health records can be traced back to the early nineties were the idea of a computer-based patient record was established. Over time this basic concept evolved in terms of scope, focus and indeed technology used to implement it, though the basic idea of providing a comprehensive, integrated and predominantly trans-institutional record that supports the provision of health services stayed the same over time [14]. Together with the concept, also the terms used for it changed such as Continuity of Care Record (CCR), Electronic Medical Record (EMR), Personal Health Record (PHR), Electronic Health Record (EHR) etc. Although the specific terms allow some inference on the basic attributes of the underlying system or conceptual characteristics, there is still no common use of terms in the literature until today. This fuzziness is less a problem for actual healthcare providers or industry but for the systematic research on the concept and has already been addressed by a number of publications e.g. $[15,16]$.

Although the exact meaning and the definition of the concept is a matter of perspective and changes over time, it seems that the term Electronic Health Record has been widely accepted and used. A simple PubMed research in November 2014 using the different terms mentioned earlier in the text confirms this assumption. The term EHR(s) outnumbers all other terms by far. The heavy use of EHR in literature started in 2009 (2010: 1266 hits; 2009: 531 hits; 2008: 239 hits). This goes together with the HITECH (Health Information Technology for Economic and Clinical Health) ACT in the US as part of the ARRA (American Recovery and Reinvestment Act) and the start of the epSOS project in the EU, which were both milestones in fostering Electronic Health Records.
Such initiatives/projects not only proliferated the use of the term but also contributed to the understanding of the concept not only with regards to a complete record about a patient but a new paradigm of cooperative, trans-institutional care.

It is widely agreed in science by now that the concept of an EHR describes a comprehensive, cross-institutional, and longitudinal collection of a patient's health and healthcare data. It, therefore, includes data that is not only particularly relevant to a subject's medical treatment but also to a subject's health in general. The patient is regarded as an active partner in his/her treatment by accessing, adding, and managing health-related data, thereby supporting care [17].

From a conceptual point, it is a fundamental question how the concept of Electronic Health Records relates to the concept of Clinical Information Systems and how these two concepts influence each other.

Trying to polarize one could state that the concept of an Electronic Health Record is characteristic for a trans-institutional, holistic, patient-centric, modern view on healthcare whereas CISs represent an intra-mural, treatment-specific, provider-centered, classical view. A lot of fundamental questions in this context seem to be unanswered such as if these two concepts share the same core and are just different views on patient data; or if EHRs are the successors of CISs on the long run; or if EHRs introduce fundamentally new elements such as patient involvement; or if they are separate systems that just share an interface. A search on PubMed and Google in November 2014 using "Dependence", "Impact", "Relation" and the two Concepts trying to find publications on these questions did not yield sufficient evidence. Although these questions seem obvious, there is hardly any literature available that deals with these questions on a conceptual and not practical basis.

Moving away from a theoretical perspective to a more practical approach, it is without a doubt that the ongoing proliferation of EHRs has a substantial practical influence on CISs.

The consequences can be illustrated by example; currently a nationwide Electronic Health Record is implemented in Austria based on a recently passed bill, with the aim 


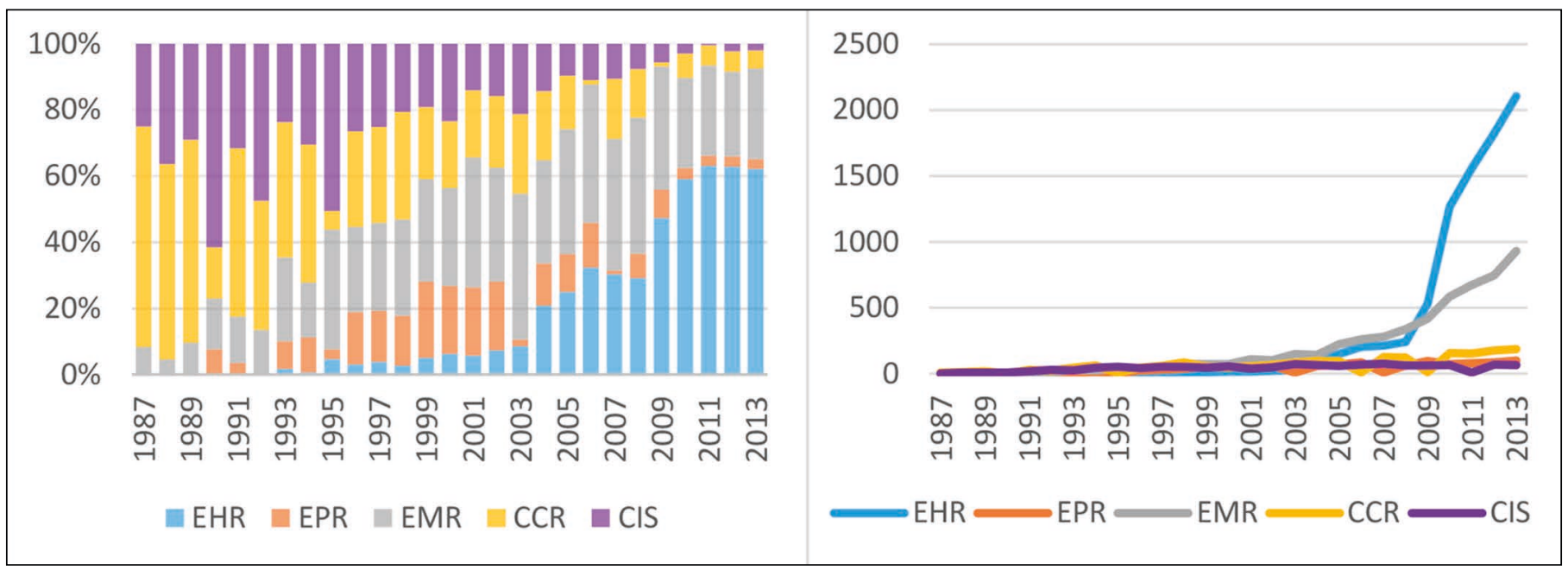

Fig. 1 Relative and absolute occurrence of selected types of records in publications for each year based on the distribution results from different PubMed searches using the singular and plural of the respective terms (e.g. "Electronic Health Record" OR "Electronic Health Records"). Abbreviations: EHR - Electronic Health Record, EPR - Electronic Patient Record, EMR - Electronic Medical Record, CCR - Continuity of Care Record, CIS - Clinical Information System.

of linking all public hospitals by the first half of 2015 and then consecutively adding further health professionals and organizations such as private hospitals, general practitioners, dentists etc. The practical impact of this initiative on CISs is significant.

In order to be able to exchange data on an inter-organizational level in a meaningful way, it is necessary to ensure interoperability on different levels. Apart from basic technical interoperability, achieving semantic interoperability has proven to require large-scale changes. It is not only necessary to use standards and (information) models but to limit these in their freedom of setting/ using specific attributes, values or coding schemes [18]. Existing CISs therefore require fundamental changes in how they store, process and transmit information. Apart from the capability of software to process information in a structured way, it is more often a problem of missing availability of structured and coded information, as clinical processes are simply not producing this kind of information (see e.g. [19]). Insufficient coding or free text fields limit the meaningful trans-organizational use of information. Although natural language processing capabilities have evolved substantially over the last years, it is still not possible to sufficiently and routinely code or structure medical free text.

\subsection{Empowering Patients}

As already introduced in section 1.1 the imperative of integrated care does not only comprise the healthcare organization and the provider side but also the patients. Apart from the patient's involvement in the actual treatment, prevention and follow-up procedures even more require the active cooperation of the patient. Although it is not scientifically proven that the integration of the patient with all means and at all points of the treatment lead to a better outcome there are certain settings where patient participation is favorable (see e.g. [20, 21]).

The concept of integrating the patient in his/her treatment is known by various terms such as patient collaboration, patient involvement, partnership, patient-empowerment or patient-centered care [22]. In addition, the related content of the concept is not well defined so far and refers to different activities regarding care ranging from education to tele-monitoring.

\subsection{Drivers for Clinical Information Systems}

Summarizing the findings from the first sections, the development of Clinical Information Systems was at their rise in the sixties primarily driven by the establishment of data pools that fostered the easy access to data for health professionals and acted as central repositories for the integration of device data. This is also reflected by the aforementioned definition of CISs that described them as large databases.

With the rise of a new paradigm - integrated care - the scope in healthcare changed and subsequently it was and still is necessary to adapt IT systems accordingly. In order to meet the changed/new requirements it is necessary to adopt an inter-organizational, collaborative and holistic perspective. The scope is no longer on institution-specific data pooling during the medical treatment of a patient but on the integration of different data sources for a patient and their meaningful use with regard to different stakeholders (including health professionals but also the patient and others) as well as different settings such as treatment, patient education, follow-up treatment etc.

A question that was already raised in the context of this paper is how CISs and EHRs are related. Depending on the perspective, one could hypothesize that EHRs are the next leap in the evolution of CISs that incorporate the basic ideas of integrated care on a conceptual level. It is indeed a difficult question to answer and probably a question of doctrine. Regardless of the definition of CISs, EHRs or other concepts and their relations, it is a fact that integration on all levels in healthcare is taking 
place. Hence, the success of any information system depends on the way how capable it is to meet the corresponding demands.

\subsection{Objective and Definitions}

The current paper aims at the identification of critical success factors and barriers for the use, implementation and conceptualization of Clinical Information Systems in integrated care settings, therefore e.g. supporting the identification of potential gaps between possible future challenges and already conducted research.

The analysis is not limited to the provider side or investigates the problem generally taking other stakeholders such as the patient into account.

Success factors are understood as groups of organizational, functional, technical or other requirements that have been identified to foster the integration or evolvement of CIS towards supporting the concept of integrated care. Barriers are understood as the opposite, hindering the proliferation of CIS. The analysis does not primarily aim for the identification of atomic requirements such as how a certain functionality e.g. the presentation of lab results needs to be implemented.

For the current analysis, Clinical Information Systems are primarily not regarded in a traditional way as e.g. described in the introduction of the paper, but as an umbrella term that covers all computerized information systems that deal with clinical data in healthcare in a broader sense. This accounts for the fact that it is very difficult and a matter of the viewpoint to precisely define the boundaries of clinical information systems in the context of integrated care. Furthermore, it is a shift from an organizational/data view on computerized information systems to a more user-centered/functional view.

\section{Methods}

In order to identify success factors and barriers for clinical information systems in integrated care settings scientific literature was searched in PubMed and Cochrane. The literature analysis was focused on the identification of existing reviews covering the respective topic.

The analysis was based on the requirements given in the PRISMA statement [23].

\subsection{Data Collection}

The search string used for data collection was composed of MeSH-Terms as well as related terms where no MeSH-Terms were available. Regardless of the source for data collection, we tried to use the same search string. In order to guarantee comparable search results for all databases we decided to include all descendants of the selected MeSH terms. To obtain the actual search string we used the MeSH-Browser of PubMed and substituted the MeSH-Terms by the indicated searchterms. Due to space limitations, the resulting search string is not provided in the paper but can be easily reproduced using the publicly available MeSH-Browser. The following search string was used to retrieve results:

("Hospital Information System*"
OR "Clinical Information System*"
OR "Electronic Medical Record*"
OR "Electronic Patient Record*" OR
"Continuity of Care Record*" OR
"Electronic Health Records"[mh]
OR "Medical Records Systems,
Computerized"[mh]) AND ("outcome*"
OR "success factors" OR "prerequisite*"
OR "requirement*" OR "experience*"
OR "integrated care" OR "assessment*"
OR "evaluation*" OR "Lesson* learned")

The collection of data was limited to (systematic) reviews and meta-analysis that were published between 1994 and 2014 and that were originally written in English language in PubMed. The same timeframe and language was used for Cochrane but due to missing filters, the initial results could not be limited to (systematic) reviews and meta-analysis, which had to be performed manually in the data analysis.

\subsection{Data Processing and Analysis}

Two researchers from the field of medical informatics processed the references that were retrieved from the different databases. Reviewers A and B separately evaluated the articles. In case of conflicts, a consensus was achieved by discussion.

In a first step, all references found were matched and duplicates were deleted. The remaining references were checked for eligibility based on their title and abstract. In order to be eligible for further processing the following in-/exclusion criteria had to be met:

- The publication is a (systematic) review or meta-analysis.

- The publication does not focus on a specific implementation of items/functions of a system e.g. a medication/laboratory functionality or the use of a certain standard.

- The publication does not focus on hardware/devices.

- The publication does not focus on clinical outcomes associated with the use of HIT.

- The system/concept under review is intended to support/enable integrated care scenarios such as the trans-institutional information exchange or the collaboration of different stakeholders.

Eligible documents were further processed using a summative content analysis as e.g. described in [24] to obtain a system of categories. After twenty percent of all papers were processed, the derived categorization system was revised in order to improve its structure and unambiguousness.

To derive success factors and barriers the coders were searching the obtained papers for statements that were either referring to ethical, organizational, technical or (non-) functional or stakeholder-related requirements that have to be met or statements that were referring to problems or barriers.

The whole process was supported by the use of the software MaxQDA 11 by VERBI.

\section{Results}

The queries in PubMed and Cochrane were performed in November 2014 and returned 1886 unique references. Analyzing the title and abstract of the retrieved references, 1818 elements could be excluded. Main 
reasons for exclusion were the focus on clinical outcomes or trials (530 references) and a mismatch in content/topic (990 references). The remaining 68 references were further analyzed for eligibility and another 28 references were excluded resulting in 40 references. See Figure 2 for an overview of the steps performed.

The number of publications for the years 2012 to 2014 account for thirty-five percent $(n=14)$ of the remaining 40 references. Seventeen publications out of forty were identified that focus especially on various aspects of clinical information systems of which seven publications have been published starting from 2012.

The identified barriers and success factors were structured according to five dimensions: organizational and conceptual, technical and non-functional, functional, data and information as well as user-related dimension.. We also decided to collect given barriers and success factors separately in order to separate both views and be able to see if there are discrepancies. Barriers and success factors can be found in Table 2 and Table 3. If one compares the share of the different categories especially when aggregating the corresponding categories from barriers and success factors over time then no outstanding differences can be observed except for the user-related category. For details, see Table 1 .

In the following paragraphs, the most important success factors and barriers for each category are introduced and further details about their characteristics are given, as these are not part of Table 2 and Table 3. For these characteristics, sources are provided exemplary but are not intended to be exhaustive.

\subsection{Organizational and Conceptual Factors}

The most important factor, which is referred to by $60 \%(n=24)$ of all publications is project and IT-management. The most important requirement given for project management is the involvement of managerial and administrative staff as well as clinical stakeholders in the planning and implementation [25-27]. It is further stated

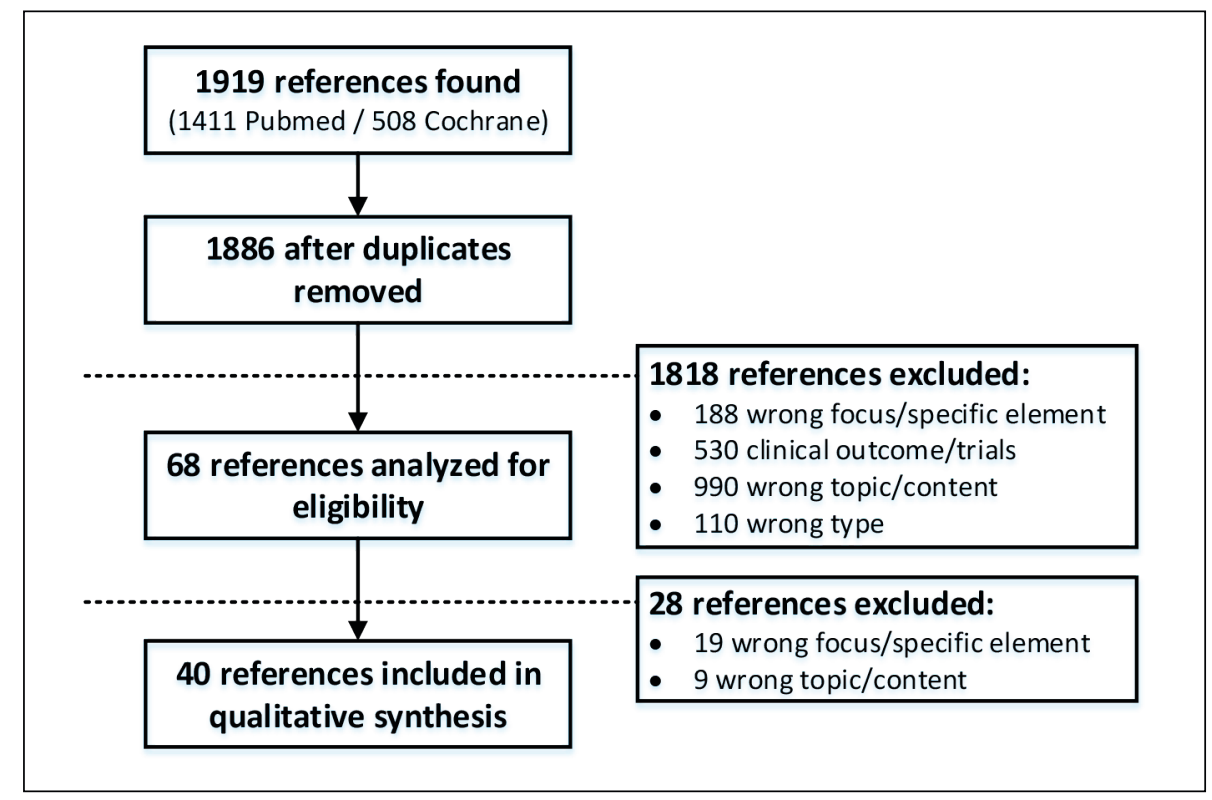

Fig. 2 Overview data collection and processing

Table 1 Percentage of total occurrence for each category based on the sum of category items with regard to barriers and success factors grouped by publications before 2012 and 2012 and later. Variation between both groups and percentage for both groups (total) is given.

\begin{tabular}{|l|c|c|c|c|}
\hline \multicolumn{3}{|c|}{ Percentage of total occurrence per category } \\
& $<2012$ & $>=2012$ & Diff. & Total \\
Barriers & & & & \\
\hline Organizational / Conceptual & $17 \%$ & $13 \%$ & $-3 \%$ & $16 \%$ \\
Technical / Non-Functional & $32 \%$ & $29 \%$ & $-3 \%$ & $31 \%$ \\
User-related & $51 \%$ & $58 \%$ & $+7 \%$ & $53 \%$ \\
Success Factors & & & & \\
\hline Organizational / Conceptual & $31 \%$ & $33 \%$ & $+2 \%$ & $32 \%$ \\
Technical / Non-Functional & $27 \%$ & $34 \%$ & $+7 \%$ & $30 \%$ \\
Functional & $7 \%$ & $3 \%$ & $-4 \%$ & $6 \%$ \\
Data and Information & $8 \%$ & $4 \%$ & $-4 \%$ & $7 \%$ \\
User-related & $26 \%$ & $27 \%$ & $0 \%$ & $26 \%$ \\
\hline
\end{tabular}

that detailed planning [28], a strategy [29], clear objectives as well as pilots $[30,31]$ are important requirements for success. These requirements can equally be found in the identified barriers (see e.g. [32]). Continuous improvement of systems [33, 34] as well as their regular evaluation $[31,35]$ are considered important for IT Management.

Training, Education and Support is the second most important element and can be found in $50 \%(\mathrm{n}=20)$ of all publications. Active user participation in training [28] and easy availability $[32,36]$ are given as important elements. This is also supported by the fact that missing IT skills $[37,38]$ are given by $10 \%(n=4)$ as a barrier to success.

Subsequently cost, outcome and workflow integration follow with around $45 \%$ $(n=18)$ each. The most important factor with regard to outcomes is regarded as the evaluation of patient outcomes [37, 39]. Other sources also refer to the necessity to learn from the outcomes of the previous system implementation processes [35] 
and to evaluate potential system outcomes through simulation [31] and testing during the process of implementation [26, 40].

It is important that systems integrate in the clinicians' daily workflows, therefore, it is important that current workflows are analyzed, understood and carefully redesigned together with clinicians [41, 43]. For this it is important to also foster collaboration on an organizational level $(28 \%, \mathrm{n}=11)[26,44]$ and consider socio-technical aspects $(10 \%$, $\mathrm{n}=4)[30,45]$.

High-cost is an important barrier [30,38] to the successful implementation of systems especially in a trans-institutional context therefore funding needs to be assured [28, $35]$ with special focus on cost-sharing [30]. Traceable return on investment $[35,46]$ is another success factor that is mentioned in the manuscripts.

\subsection{Technical and Non-Functional \\ Factors}

Data security and privacy are amongst the most important success factors, which can be found in many publications that focus on inter-organizational information systems. Summarizing barriers and success factors, around $50 \%$ of all analyzed publications refer to security issues. Encryption [47], comprehensive logging [48] and user education [47] are regarded as important measures in this context.

Other important and observed factors can be grouped together as core to trans-institutional information systems and include systems interoperability $(23 \%, \mathrm{n}=9)$, holistic standardization ( $38 \%, \mathrm{n}=15)$, support for communication and data exchange $(33 \%, n=13)$, system flexibility $(33 \%, \mathrm{n}=13)$ and integrated systems $(28 \%$, $\mathrm{n}=11$ ). With regard to this group of factors, many requirements could be found. In order to create successful systems standards need to be applied extensively on different levels. The majority of papers refer to standardized terminologies [49], documents [40] and messaging [46], but also the support of clinical protocols [26] and standardized export formats [39] are mentioned. Furthermore interdepartmental or even inter-organizational communica- tion of different health professionals, not restricted to clinical data needs to be supported within the systems [50-52]. Flexibility is a further claim $[46,53]$; systems need to be adaptable [29] especially in line with organizational changes or changes in care delivery (processes) [32]. Corresponding barriers are mentioned in terms of missing standards $(8 \%, \mathrm{n}=3)[28,54]$, poor system integration $(8 \%, \mathrm{n}=3)[32,48]$ or inflexible to changes $(8 \%, \mathrm{n}=3)$ [36].

Systems need to find a balance between stability and flexibility [35]. Performance and response time $(30 \%, \mathrm{n}=12)[35,42]$ as well as availability and reliability $(25 \%, \mathrm{n}=10)[29$, 55] are important success factors, which are also part of the identified barriers [37].

\subsection{Functional and Information- related Factors}

Because we analyzed systematic reviews and meta-analysis but excluded manuscripts that are dedicated to a specific function or system, the number of observed functions is low. Nonetheless, certain basic functions were found. Decision support $(25 \%, \mathrm{n}=10)$ [31, $39,55]$ was identified most often followed by reminders/alerts/notifications $(15 \%$, $\mathrm{n}=6)$ [37, 39, 42], support for automation $(8 \%, \mathrm{n}=3)[39,40,51]$ and support for the secondary use of data $(8 \%, n=3)[40,49,57]$.

Information-related factors included the claim for easy access to and provision of comprehensive patient data $(35 \%, n=14)$

Table 2 Barriers to the successful implementation and conceptualization of clinical information systems. (For each barrier the identified references are provided as well as the absolute number and percentage of occurrences is given. Occurrences are only counted once per publication. Total number of publications $n=40$.)

\begin{tabular}{|c|c|c|c|}
\hline Barriers & References & $\mathrm{N}$ & $\%$ \\
\hline \multicolumn{4}{|l|}{ Organizational / Conceptual } \\
\hline Missing managerial support & {$[32]$} & 1 & $3 \%$ \\
\hline Enforced implementation & {$[28,51]$} & 2 & $5 \%$ \\
\hline Insufficient project planing & {$[27,28,48]$} & 3 & $8 \%$ \\
\hline Missing resources & {$[37,51,56]$} & 3 & $8 \%$ \\
\hline Different views on processes/routines & {$[25-27,36,45]$} & 5 & $13 \%$ \\
\hline High cost & {$[30,32,38,51,57]$} & 5 & $13 \%$ \\
\hline \multicolumn{4}{|l|}{ Technical / Non-Functional } \\
\hline Complex information needs & {$[32]$} & 1 & $3 \%$ \\
\hline Data overflow & {$[28]$} & 1 & $3 \%$ \\
\hline Poor system integration & {$[32,48,51]$} & 3 & $8 \%$ \\
\hline Missing standards and guidelines & {$[28,54,58]$} & 3 & $8 \%$ \\
\hline Inflexible to changes & {$[32,36,48]$} & 3 & $8 \%$ \\
\hline Poor data quality & {$[25,32,39,51,58,59]$} & 6 & $15 \%$ \\
\hline Poor system reliability and response time & {$[32,36-38,40,51]$} & 6 & $15 \%$ \\
\hline Inconvenient/poor system design & {$[31,34,36,37,46,51]$} & 6 & $15 \%$ \\
\hline Data Security and Privacy Concerns & {$[28,30,32,36,47,56,59,60]$} & 8 & $20 \%$ \\
\hline \multicolumn{4}{|l|}{ User-related } \\
\hline Increased accountability/liability & {$[30]$} & 1 & $3 \%$ \\
\hline Dependence on technology & [48] & 1 & $3 \%$ \\
\hline Missing IT skills & {$[32,37,38,51]$} & 4 & $10 \%$ \\
\hline Insufficient communication during/after implementation & {$[26,28,36,48,51]$} & 5 & $13 \%$ \\
\hline Change of established processes/workflows & {$[26,28,30,36,38,40,46,48,51]$} & 9 & $23 \%$ \\
\hline $\begin{array}{l}\text { Changes to physician-patient relation (dehumanized } \\
\text { patient care) }\end{array}$ & {$[28,30-32,34,37,46,48,51,56,60]$} & 11 & $28 \%$ \\
\hline Missing involvement of users in the development & $\begin{array}{l}{[25,27-29,31,32,35,36,38,51,} \\
56,59]\end{array}$ & 12 & $30 \%$ \\
\hline Increased clinicians' time/effort & $\begin{array}{l}{[26,28,30-32,34,36,38,40,42,45,} \\
48,51,52,56,57,60-62]\end{array}$ & 19 & $48 \%$ \\
\hline
\end{tabular}


$[32,59]$ as well as accuracy $(18 \%, \mathrm{n}=7)[28$, $33]$ and consistence $(8 \%, \mathrm{n}=3)[28,36]$ of data within information systems. Another success factor is meaningful possibilities to aggregate and group data $(8 \%, n=3)[34,49]$.

\subsection{User-related Factors}

An increase in time that clinicians spend for documentation and data retrieval (48\%, $\mathrm{n}=19$ ) due to new systems is identified as a major barrier. Reasons for this are poor system usability [28], multiple documentation [45] or distracting alerts [48]. This is also supported by the corresponding success factors such as the perceived usefulness for the users $(55 \%, \mathrm{n}=22)$ or usability $(60 \%, n=24)$. Factors that increase the perceived usefulness include an increased productivity $[28,56]$, a clear motivation and explanation for the implementation of a new system [48] or the satisfaction of individual information needs [29]. Usability is amongst others influenced by an intuitive use [34, 38], a user-centered design [26], possibilities to adapt the system to specific user-behaviors [33, 52] and efficient use through e.g. automatic data provision [55], data filtering [51] or real-time data analysis [32].

Several barriers and success factors are dedicated to the involvement of users in the conceptualization and implementation of new systems. Important barriers in this context are the missing involvement of users (health professionals and patients) in the system development $(30 \%, \mathrm{n}=12)$ [27, 36 and insufficient communication during/ after implementation $(13 \%, \mathrm{n}=5)[26,48]$. Success factors include an adequate and constant motivation of staff $(35 \%, n=14)$ through activities [35], incentives [42, 60] and information (31), the involvement of all stakeholders in the process of implementation $(60 \%, n=24)[25,43]$ and the structured management of user concerns/ feedback $(28 \%, n=11)$ [27, 32]. Involving all stakeholders implies actions such as the identification of key actors/champions [26, 30], establishing interdisciplinary working groups (administration, patients, clinicians etc.) $[29,30]$ or the compensation of time needed [26].
Table 3 Success Factors for the implementation and conceptualization of dinical information systems. (For each successfactor the identified references are provided as well as the absolute number and percentage of occurrences is given. Occurrences are only counted once per publication. Total number of publications $\mathrm{n}=40$.)

\begin{tabular}{|c|c|c|c|}
\hline Success Factors & References & $N$ & $\%$ \\
\hline \multicolumn{4}{|l|}{ Organizational / Conceptual } \\
\hline System Certification & {$[30]$} & 1 & $3 \%$ \\
\hline Consider ethical requirements & {$[35,47,51]$} & 3 & $8 \%$ \\
\hline Consider socio-technical system aspects & {$[30,35,45,48]$} & 4 & $10 \%$ \\
\hline Establish steering committee, user groups & {$[30,32,40,60,63]$} & 5 & $13 \%$ \\
\hline Consider political issues (external/in-house) & {$[25,26,29,35,41,42,45,47,50,60,63]$} & 11 & $28 \%$ \\
\hline Foster collaboration on an organizational level & {$[26-29,31,35,44,46,48,51,62]$} & 11 & $28 \%$ \\
\hline Costs/Economy & {$[26,28-30,32,34-38,46,60,62]$} & 13 & $33 \%$ \\
\hline Outcome assessment/evaluation & {$[26,28,29,31-37,39,40,42,46,48,51,57,62]$} & 18 & $45 \%$ \\
\hline Integration of Systems in clinical workflows & {$[26,29-31,34,35,37,40-43,46,48,51,55,61-63]$} & 18 & $45 \%$ \\
\hline Training, Education and Support & {$[26-33,35-37,39,40,47,48,51,55,56,62,63]$} & 20 & $50 \%$ \\
\hline Project and IT management & {$[25-35,37,38,40,42,48,50,51,56,59-63]$} & 24 & $60 \%$ \\
\hline \multicolumn{4}{|l|}{ Technical / Non-Functional } \\
\hline Reliable backup systems & [39] & 1 & $3 \%$ \\
\hline Readiness for Internet & {$[32,44,59]$} & 3 & $8 \%$ \\
\hline Mature systems & {$[26,29,30,42,61,63]$} & 6 & $15 \%$ \\
\hline Support for ubiquitous computing & {$[28,29,32,39,54,61]$} & 6 & $15 \%$ \\
\hline Guarantee Privacy & {$[28,29,35,41,45,53,63]$} & 7 & $18 \%$ \\
\hline Systems Interoperability & {$[28,35,42,45,49,52,53,56,60]$} & 9 & $23 \%$ \\
\hline Availability and Reliability & {$[28,29,35,36,39,42,51,53,55,61]$} & 10 & $25 \%$ \\
\hline Integrated Systems & {$[26-28,32,35,43,46,55,57,61,63]$} & 11 & $28 \%$ \\
\hline Performance and Response time & {$[26,29,31,33,35,36,39,42,44,51,52,55]$} & 12 & $30 \%$ \\
\hline Support communication and data exchange & {$[28,33,36,39,40,43-45,49-52,54]$} & 13 & $33 \%$ \\
\hline System flexibility & {$[26,28,29,32,34,35,39,42,45,46,53,55,58]$} & 13 & $33 \%$ \\
\hline Guarantee Data security & {$[25,28,29,32,33,35,41,45,47,48,53,55,61,63]$} & 14 & $35 \%$ \\
\hline Holistic Standardization & $\begin{array}{l}{[26,30,32,33,35,36,39,40,45,46,49,53,55,} \\
58,60]\end{array}$ & 15 & $38 \%$ \\
\hline \multicolumn{4}{|l|}{ Functional } \\
\hline Situation awareness & [39] & 1 & $3 \%$ \\
\hline Sufficient help feature & {$[52]$} & 1 & $3 \%$ \\
\hline Support for secondary use of data & {$[40,49,57]$} & 3 & $8 \%$ \\
\hline Support for automation & {$[39,40,51]$} & 3 & $8 \%$ \\
\hline Reminders/Alerts/Notifications & {$[34,37,39,42,51,52]$} & 6 & $15 \%$ \\
\hline Decision support & {$[26,28,31,34,36,37,39,42,55,57]$} & 10 & $25 \%$ \\
\hline \multicolumn{4}{|l|}{ Data and Information } \\
\hline Strategies to decrease data entry errors & {$[32]$} & 1 & $3 \%$ \\
\hline Novell patient identification strategies & [39] & 1 & $3 \%$ \\
\hline Consistent data & {$[28,36,53]$} & 3 & $8 \%$ \\
\hline Data aggregation possibilities & {$[34,39,49]$} & 3 & $8 \%$ \\
\hline Data accuracy & {$[28,31,33,36,40,53,55]$} & 7 & $18 \%$ \\
\hline Provide (access to) comprehensive patient data & {$[28,32-34,36-39,42,51,57-59,61]$} & 14 & $35 \%$ \\
\hline \multicolumn{4}{|l|}{ User-related } \\
\hline Sufficient access to computers & {$[29,33,55]$} & 3 & $8 \%$ \\
\hline User readiness/previous experiences & {$[28-30,35,37,42,59]$} & 7 & $18 \%$ \\
\hline Manage user concerns/feedback & {$[27,29-34,37,48,55,63]$} & 11 & $28 \%$ \\
\hline Encourage/motivate staff & {$[26,28,29,31-33,35-37,42,55,56,60,62]$} & 14 & $35 \%$ \\
\hline Perceived usefulness for the user & $\begin{array}{l}{[26,28,29,32-36,38-41,43,44,48,51-53} \\
55-57,59]\end{array}$ & 22 & $55 \%$ \\
\hline Include all stakeholders in the implementation process & {$[25-33,35,37,40,42,43,46,48,51,54-56,59-61,64]$} & 24 & $60 \%$ \\
\hline Usability & {$[26,28,29,32-39,41-44,48,51-53,55,59,61-63]$} & 24 & $60 \%$ \\
\hline
\end{tabular}


Further important barriers are changes to the physician-patient relation (dehumanized patient care $)(28 \%, n=11)[30,56]$ and changes to established processes and workflows $(23 \%, \mathrm{n}=9)[48,51]$.

\subsection{Comparing the Focus of Publications over Time}

With the rise of different technological concepts, ideas or organizational paradigms over time one can often observe a shift in the focus of publications. Therefore, we have compared publications prior to $2012(\mathrm{n}=26)$ and recent publications (2012-2014, $\mathrm{n}=14)$ with regard to their focus on certain aspects observed in our analysis. The comparison is based on the relative occurrence of factors within the publications and only covers a decrease or increase of occurrence higher than $\pm 15 \%$. A detailed overview of the changes can be found in Table 4 and Table 5 . The highest increase could be observed for the success factors: the consideration of (external/in-house) political issues ( $+24 \%)$, the inclusion off all stakeholder in the process of implementation (+21\%) and the support of ubiquitous computing $(+21 \%)$.

The highest decrease was observed for: providing access to comprehensive patient data $(-32 \%)$, pursuing a holistic standardization approach $(-25 \%)$ and the necessity to evaluate the outcome of systems $(-25 \%)$ together with the barrier to change existing workflows and processes $(-24 \%)$.

It is important to note that a decrease or increase does not necessarily imply a decrease or increase in importance but often a shift in focus or that certain matters have been resolved. A good example for the necessity to cautiously interpret the results is the decrease with regard to the increase of the item "Systems interoperability" and decrease of the item "Holistic Standardization".

\subsection{A Quick Look on Outcomes}

For the primary goal of the manuscript, the identification of barriers and success factors, we have actually excluded references that were focusing on the analysis of outcomes of clinical information systems. Nevertheless,

Table 4 Selected success factors and barriers with a relative increase in occurrence in publications of $>=15 \%$, comparing publications prior to 2012 and between 2012 and 2014

\begin{tabular}{|c|c|c|c|c|c|}
\hline & \multicolumn{2}{|c|}{$2012-2014(N=14)$} & \multicolumn{2}{|c|}{ prior $2012(\mathrm{~N}=26)$} & \multirow{2}{*}{$\frac{\text { Increase }(>=15 \%)}{\%}$} \\
\hline & $\mathrm{N}$ & $\%$ & $\mathrm{~N}$ & $\%$ & \\
\hline \multicolumn{6}{|l|}{ Success Factors } \\
\hline \multicolumn{6}{|c|}{ Organizational/Conceptual } \\
\hline Consider political issues (external/in-house) & 6 & $43 \%$ & 5 & $19 \%$ & $+24 \%$ \\
\hline \multicolumn{6}{|c|}{ User-related } \\
\hline $\begin{array}{l}\text { Include all stakeholders in the implementation } \\
\text { process }\end{array}$ & 10 & $71 \%$ & 13 & $50 \%$ & $+21 \%$ \\
\hline Encourage/motivate staff & 6 & $43 \%$ & 7 & $27 \%$ & $+16 \%$ \\
\hline \multicolumn{6}{|c|}{ Technical/Non-Functional } \\
\hline Support for ubiquitous computing & 4 & $29 \%$ & 2 & $8 \%$ & $+21 \%$ \\
\hline Systems Interoperability & 5 & $36 \%$ & 4 & $15 \%$ & $+20 \%$ \\
\hline Guarantee Data security & 6 & $43 \%$ & 7 & $27 \%$ & $+16 \%$ \\
\hline
\end{tabular}

Table 5 Selected success factors and barriers with a relative decrease in occurrence in publications of $>=15 \%$, comparing publications prior to 2012 and between 2012 and 2014.

\begin{tabular}{|c|c|c|c|c|c|}
\hline & \multicolumn{2}{|c|}{$2012-2014(\mathrm{~N}=14)$} & \multicolumn{2}{|c|}{ prior $2012(\mathrm{~N}=26)$} & \multirow{2}{*}{$\begin{array}{c}\text { Decrease }(>=15 \%) \\
\%\end{array}$} \\
\hline & $\mathrm{N}$ & $\%$ & N & $\%$ & \\
\hline \multicolumn{6}{|l|}{ Success Factors } \\
\hline \multicolumn{6}{|c|}{ User-related } \\
\hline Perceived usefulness for the user & 7 & $50 \%$ & 15 & $58 \%$ & $-8 \%$ \\
\hline Manage user concerns/feedback & 3 & $21 \%$ & 8 & $31 \%$ & $-10 \%$ \\
\hline Usability & 7 & $50 \%$ & 17 & $65 \%$ & $-15 \%$ \\
\hline \multicolumn{6}{|c|}{ Technical/Non-Functional } \\
\hline Holistic Standardization & 3 & $21 \%$ & 12 & $46 \%$ & $-25 \%$ \\
\hline \multicolumn{6}{|c|}{ Organizational / Conceptional } \\
\hline $\begin{array}{l}\text { Integration of Systems in Workflows, } \\
\text { Healthcare Processes }\end{array}$ & 5 & $36 \%$ & 13 & $50 \%$ & $-14 \%$ \\
\hline Outcome assessment/evaluation & 4 & $29 \%$ & 14 & $54 \%$ & $-25 \%$ \\
\hline \multicolumn{6}{|c|}{ Data and Information } \\
\hline $\begin{array}{l}\text { Provide (access to) comprehensive patient data } \\
\text { Barriers }\end{array}$ & 2 & $14 \%$ & 12 & $46 \%$ & $-32 \%$ \\
\hline \multicolumn{6}{|c|}{ User-related } \\
\hline Missing IT skills & 0 & $0 \%$ & 4 & $15 \%$ & $-15 \%$ \\
\hline Change of established processes/workflows & 1 & $7 \%$ & 8 & $31 \%$ & $-24 \%$ \\
\hline \multicolumn{6}{|c|}{ Technical/Non Functional } \\
\hline Poor system reliability and response time & 0 & $0 \%$ & 6 & $23 \%$ & $-23 \%$ \\
\hline \multicolumn{6}{|c|}{ Organizational/Conceptional } \\
\hline High cost & 0 & $0 \%$ & 5 & $19 \%$ & $-19 \%$ \\
\hline
\end{tabular}

a positive outcome is probably one of the major success factors on the long run so we decided not to completely skip on outcomes. We have therefore analyzed the excluded references ( $\mathrm{n}=81$; reason for exclusion: con- tent describes clinical outcome) with regard to the basic subject, they are dealing with.

The majority of outcomes research regarding specific functionality was dedicated to CDSS - Clinical Decision Support 
Systems ( $\mathrm{n}=14,17 \%)$ and CPOE - Clinical Provider Order Entry Systems ( $\mathrm{n}=17,21 \%)$. Outcome of CDSS and CPOE systems were most often analyzed with regard to medication or their influence on medication errors. More general reviews were dedicated to EHR - Electronic Health Records ( $\mathrm{n}=10$, 12\%), EMR - Electronic Medical Records $(\mathrm{n}=14,17 \%)$ and HIT - Health Information Technology $(\mathrm{n}=10,12 \%)$ in general. A specific focus of EHR, EMR or HIT outcomes reviews could not be identified; topics were ranging from their impact on certain disease such as diabetes to their organizational or process-specific impact. Restricting the results to the years $2012-2014$ a similar distribution of subjects could be found.

Although it is not possible to provide a detailed summary of the results at this point we found clear evidence from the papers that neither of the concepts does provide benefits with regard to (clinical) outcome per se. The predominant number of publications conclude that benefits are subject to a specific organizational and functional setting regardless of the (technological) maturity of concepts. This can best be observed by comparing reviews over time (see e.g. [33, 65-68]).

\section{Discussion}

The following paragraphs briefly summarize important findings from our study and discuss the limitations and generalizability.

\subsection{Summary of Evidence}

We were able to identify several barriers and success factors related to Clinical Information Systems in a broader sense. Still, the number of publications explicitly referring to the term Clinical Information System in their title or within the text was limited. Publications predominantly did not define a clear or explicit conceptual scope regarding the system under review and additionally were using different definitions or investigating multiple conceptual concepts at once. This was not surprising to us, as we have experienced the same difficulties setting the scope of the present manuscript. There is apparently a need for clarification and reflection of the established concepts with regard to their suitability within the domain of integrated care.

Regarding potential stakeholders, the focus was clearly set on healthcare professionals for the majority of publications. Patient specific barriers and success factors were mentioned and occasionally requirements were analyzed in more detail but the overall occurrence was comparably low. There are indeed numerous publications available that analyze user-needs in a specific context or for a specific system but rarely any publications that put these in a broader context. This is an interesting finding as integrated care explicitly refers to the active involvement of patients. Therefore, it can be considered as an important but not well-explored field.

It is striking that the majority of barriers and success factors are fairly constant over time respectively in the publications. This perception is also supported by the observed results from the outcome studies. The question arises whether research results are sufficiently transferred to practice.

\subsection{Limitations}

The success factors and barriers were acquired through a qualitative content analysis of available reviews and meta-analyses by two independent coders. The manuscripts were obtained through PubMed and Cochrane. Although the approach was defined and discussed in advance, we may have overlooked relevant publications. Also the selection of literature and especially its coding finally depends on the coders. Selection and coding bias was reduced by the definition of keywords, in-/exclusion criteria and the discussion of codings but cannot be eliminated, directly influencing the validity and completeness of the results.

As there is no commonly agreed view on the boundaries of Clinical Information Systems with regard to integrated care scenarios, we have chosen a holistic view for the current study including different concepts such as EMRs or EHRs in our analysis. This decision influences the specificity of results and relevant details may be lost. On the other hand, the current approach compen- sates different use of terms and definitions and supports the identification of common success factors and barriers of information systems in a trans-institutional setting.

The low number of available manuscripts that could be found using the term "Clinical Information System" or corresponding modifications encouraged us as well to decide in favor of a holistic approach.

\subsection{Generalizability}

Apart from the previously discussed limitations, the results of the current study are based on solid evidence as the source manuscripts only included systematic reviews and meta-analysis. During the selection of manuscripts, we have also excluded manuscripts that did not meet the methodological criteria of a systematic review or meta-analysis even if the title or search engine categorization provided a different indication. Therefore, each factor presented in the current manuscript even if having an occurrence of one is in turn based on a systematic review and multiple sources.

\section{Conclusion}

The current review clearly illustrates that ongoing changes in healthcare such as increasingly disappearing organizational boundaries on an informational level, specialization in care or the alignment of care along trans-institutional processes require a fundamental rethinking of established assumptions and doctrine with regard to (computerized) information systems including clinical information systems.

It is important to learn from the experiences made/collected over time and finally adapt to these requirements as e.g. provided in the current manuscript. Interestingly the experienced barriers/success factors or in other words committed faults somehow seem to remain almost unvaried over time.

In order to support further systematic investigations on the matter it is necessary to clarify, extend or even fundamentally change existing concepts and definitions to realign them with the ideas of integrated care. 


\section{References}

1. Jydstrup RA, Gross MJ. Cost of information handling in hospitals. Health Serv Research 1966;1(3):235-71.

2. Staggers N, Thompson CB, Snyder-Halpern R. History and trends in clinical information systems in the United States. J Nurs Scholarsh 2001;33(1):75-81.

3. Pryor TA, Gardner RM, Clayton PD, Warner HR. The HELP system. J Med Syst 1983;7(2):87-102.

4. Lenhard RE, Blum BI, Sunderland JM, Braine HG, Saral R. The Johns Hopkins Oncology Clinical Information System. J Med Syst 1983;7(2):147-74.

5. Blum BI. Clinical information systems-a review. West J Med 1986;145(6):791-7.

6. Kodner DL, Spreeuwenberg C. Integrated care: meaning, logic, applications, and implications - a discussion paper. Int J Integr Care 2002;2:e12.

7. Kodner DL. All together now: a conceptual exploration of integrated care. Healthc Q 2009;13 Spec No:6-15.

8. Delnoij D, Klazinga N, Glasgow IK. Integrated care in an international perspective. Int J Integr Care 2002;2;e04.

9. Nolte E, McKee M. Caring for people with chronic conditions: A health system perspective. Maidenhead, England: Open University Press; 2008. (European Observatory on Health Systems and Policies series).

10. Ouwens M, Wollersheim H, Hermens R, Hulscher M, Grol R. Integrated care programmes for chronically ill patients: a review of systematic reviews. Int J Qual Health Care 2005 Apr; 17(2):141-6.

11. Lloyd J, Wait S. Integrated Care: A Guide for Policymakers: Alliance for Health and the Future; 2006

12. Kodner DL, Spreeuwenberg C. Integrated care: meaning, logic, applications, and implications--a discussion paper. Int J Integr Care 2002;2:e12.

13. Leutz WN. Five Laws for Integrating Medical and Social Services: Lessons from the United States and the United Kingdom. Milbank Q 1999;77(1):77-110.

14. Hörbst A, Ammenwerth E. Quality and Certification of Electronic Health Records An overview of current approaches from the US and Europe. Appl Clin Inform 2010;1(2):149-64.

15. Waegemann CP. EHR vs. CPR vs. EMR. Healthcare Informatics Online 2003; (May):1-4.

16. Waegemann CP. Current Status of EPR Developments in the US. In: Toward an Electronic Health Record '99, Medical Records Institute; 1999. p. 116-8

17. Ball M, Smith C, Bakalar RS. Personal Health Records: Empowering Consumers. J Healthc Inf Manag 2006;21(1):76-86

18. Oemig F, Blobel B. Semantic interoperability adheres to proper models and code systems. A detailed examination of different approaches for score systems. Methods Inf Med 2010;49(2):148-55

19. Scherb CA, Maas ML, Head BJ, Johnson MR, Kozel M, Reed D, et al. Implications of electronic health record meaningful use legislation for nursing clinical information system development and refinement. Int J Nurs Knowl 2013;24(2):93-100.
20. Ammenwerth E, Schnell-Inderst P, Hoerbst A. The impact of electronic patient portals on patient care: A systematic review of controlled trials. J Med Internet Res 2012;14(6):e162.

21. Meijer WJ, Ragetlie PL. Empowering the patient with ICT-tools: the unfulfilled promise. Stud Health Technol Inform 2007;127:199-218.

22. Longtin Y, Sax H, Leape LL, Sheridan SE, Donaldson L, Pittet D. Patient participation: current knowledge and applicability to patient safety. Mayo Clinic proceedings 2010;85(1):53-62.

23. Moher D, Liberati A, Tetzlaff J, Altman DG. Preferred reporting items for systematic reviews and meta-analyses: the PRISMA statement. BMJ 2009;339:b2535

24. Mayring P. Qualitative Content Analysis. Forum Qualitative Sozialforschung / Forum: Qualitative Social Research; Vol 1, No 2 (2000): Qualitative Methods in Various Disciplines I: Psychology 2000 [cited 2000].

25. Featherstone I, Keen J. Do integrated record systems lead to integrated services? An observational study of a multi-professional system in a diabetes service. Int $\mathrm{J}$ Med Inform 2012;81(1):45-52. Available from: URL:http:// search.ebscohost.com/login.aspx?direct=true\&d$\mathrm{b}=$ aph\&AN $=69954948 \&$ site $=$ ehost-live.

26. Peute LW, Aarts J, Bakker, Piet JM, Jaspers, Monique WM. Anatomy of a failure: a sociotechnical evaluation of a laboratory physician order entry system implementation. Int J Med Inform 2010;79(4):e58-70.

27. Rahimi B, Vimarlund V, Timpka T. Health information system implementation: a qualitative meta-analysis. J Med Syst 2009;33(5):359-68.

28. Nguyen L, Bellucci E, Nguyen LT. Electronic health records implementation: an evaluation of information system impact and contingency factors. Int J Med Inform 2014;83(11):779-96.

29. Boonstra A, Versluis A, Vos, Janita F J. Implementing electronic health records in hospitals: a systematic literature review. BMC Health Serv Res 2014; $14: 370$

30. Ludwick DA, Doucette J. Adopting electronic medical records in primary care: lessons learned from health information systems implementation experience in seven countries. Int J Med Inform 2009; 78(1):22-31

31. Kelay T, Kesavan S, Collins RE, Kyaw-Tun J, Cox $\mathrm{B}$, Bello F, et al. Techniques to aid the implementation of novel clinical information systems: a systematic review. Int J Surg 2013;11(9):783-91.

32. Stolee P, Steeves B, Glenny C, Filsinger S. The use of electronic health information systems in home care: facilitators and barriers. Home Healthc Nurse 2010;28(3):167-79; quiz 180-1.

33. Gruber D, Cummings GG, LeBlanc L, Smith DL. Factors influencing outcomes of clinical information systems implementation: a systematic review. Comput Inform Nurs 2009;27(3):151-63; quiz 164-5.

34. Khajouei R, Jaspers, MWM. The impact of CPOE medication systems' design aspects on usability, workflow and medication orders: a systematic review. Methods Inf Med 2010;49(1):3-19.

35. Sadoughi F, Kimiafar K, Ahmadi M, Shakeri MT. Determining of factors influencing the success and failure of hospital information system and their evaluation methods: a systematic review. Iran Red Crescent Med J 2013;15(12):e11716.

36. Van Der Meijden, MJ, Tange HJ, Troost J, Hasman A. Determinants of success of inpatient clinical information systems: a literature review. JAm Med Inform Assoc 2003;10(3):235-43.

37. Huryk LA. Factors influencing nurses' attitudes towards healthcare information technology. J Nurs Manag 2010;18(5):606-12.

38. Goldzweig CL, Towfigh A, Maglione M, Shekelle PG. Costs and benefits of health information technology: new trends from the literature. Health Aff (Millwood) 2009;28(2):w282-93.

39. Feied CF, Handler JA, Smith MS, Gillam M, Kanhouwa M, Rothenhaus T, et al. Clinical information systems: instant ubiquitous clinical data for error reduction and improved clinical outcomes. Acad Emerg Med 2004;11(11):1162-9.

40. Vreeman DJ, Taggard SL, Rhine MD, Worrell TW. Evidence for electronic health record systems in physical therapy. Phys Ther 2006;86(3):434-46; discussion 446-9.

41. Croll PR, Croll J. Investigating risk exposure in e-health systems. Int J Med Inform 2007;76(56):460-5.

42. Lau F, Kuziemsky C, Price M, Gardner J. A review on systematic reviews of health information system studies. J Am Med Inform Assoc 2010;17(6):637-45.

43. Nies J, Colombet I, Degoulet P, Durieux P. Determinants of success for computerized clinical decision support systems integrated in $\mathrm{CPOE}$ systems: a systematic review. AMIA Annu Symp Proc 2006:594-8.

44. Clarke MA, Belden JL, Koopman RJ, Steege LM, Moore JL, Canfield SM, et al. Information needs and information-seeking behaviour analysis of primary care physicians and nurses: a literature review. Health Info Libr J 2013;30(3):178-90.

45. Knaup P, Bott O, Kohl C, Lovis C, Garde S. Electronic patient records: moving from islands and bridges towards electronic health records for continuity of care. Yearb Med Inform 2007:34-46.

46. Winkelman WJ, Leonard KJ. Overcoming structural constraints to patient utilization of electronic medical records: a critical review and proposal for an evaluation framework. J Am Med Inform Assoc 2004;11(2):151-61.

47. Fernandez-Aleman JL, Senor IC, Lozoya, Pedro Angel Oliver, Toval A. Security and privacy in electronic health records: a systematic literature review. J Biomed Inform 2013;46(3):541-62.

48. Ozdas A, Miller RA. Care provider order entry (CPOE): a perspective on factors leading to success or to failure. Yearb Med Inform 2007:128-37.

49. Westra BL, Delaney CW, Konicek D, Keenan G Nursing standards to support the electronic health record. Nurs Outlook 2008;56(5):258-266.e1.

50. Chung, Vincent C H, Ma, Polly H X, Hong LC, Griffiths SM. Organizational determinants of interprofessional collaboration in integrative health care: systematic review of qualitative studies. PLoS One 2012;7(11):e50022.

51. Holden RJ. Physicians' beliefs about using EMR and CPOE: In pursuit of a contextualized understanding of health it use behavior. Int J Med Inform 2010;79(2):71-80. Available from: URL:http:// search.ebscohost.com/login.aspx?direct=true\&d- 
b=aph\&AN=47642429\&site=ehost-live.

52. Liu J, Luo L, Zhang R, Huang T. Patient satisfaction with electronic medical/health record: a systematic review. Scand J Caring Sci 2013;27(4):785-91.

53. Hoerbst A, Ammenwerth E. Electronic health records. A systematic review on quality requirements. Methods Inf Med 2010;49(4):320-36.

54. Prey JE, Woollen J, Wilcox L, Sackeim AD, Hripcsak G, Bakken S, et al. Patient engagement in the inpatient setting: a systematic review. J Am Med Inform Assoc 2014;21(4):742-50.

55. Mollon B, Chong J, JR, Holbrook AM, Sung M, Thabane L, Foster G. Features predicting the success of computerized decision support for prescribing: a systematic review of randomized controlled trials. BMC Med Inform Decis Mak 2009;9:11.

56. McGinn CA, Gagnon M, Shaw N, Sicotte C, Mathieu L, Leduc Y, et al. Users' perspectives of key factors to implementing electronic health records in Canada: a Delphi study. BMC Med Inform Decis Mak 2012;12(1):105-17. Available from: URL:http://search.ebscohost.com/login.aspx?direct=true \& $\mathrm{db}=\mathrm{aph} \& \mathrm{AN}=83356444 \&$ site $=\mathrm{e}-$ host-live.

57. Fraenkel DJ. Clinical information systems in intensive care. Crit Care Resusc 1999;1(2):179.

58. Dolin RH. Outcome analysis: considerations for an electronic health record. MD Comput 1997;14(1):50-6.

59. Hardiker NR, Grant MJ. Barriers and facilitators that affect public engagement with eHealth services. Stud Health Technol Inform 2010;160(Pt 1):13-7.

60. Mair FS, May C, O’Donnell C, Finch T, Sullivan F, Murray E. Factors that promote or inhibit the implementation of e-health systems: an explanatory systematic review. Bull World Health Organ 2012;90(5):357-64.

61. Buhk J, Fleischer M. Radiology in combination with hospital communication - challenges, solutions and pitfalls: Radiology IT as important component of electronic patient records in the University Hospital Hamburg-Eppendorf (UKE). Radiologe 2014;54(1):9-18.

62. Ash JS, Stavri PZ, Kuperman GJ. A consensus statement on considerations for a successful CPOE implementation. J Am Med Inform Assoc 2003;10(3):229-34.

63. Keshavjee K, Bosomworth J, Copen J, Lai J, Kucukyazici B, Lilani R, et al. Best practices in EMR implementation: a systematic review. AMIA Annu Symp Proc 2006:982.

64. Goldzweig CL, Orshansky G, Paige NM, Towfigh AA, Haggstrom DA, Miake-Lye I, et al. Electronic patient portals: evidence on health outcomes, satisfaction, efficiency, and attitudes: a systematic review. Ann Intern Med 2013;159(10):677-87.

65. Kaushal R, Shojania KG, Bates DW. Effects of computerized physician order entry and clinical decision support systems on medication safety: a systematic review. Arch Intern Med
2003;163(12):1409-16.

66. Holroyd-Leduc JM, Lorenzetti D, Straus SE, Sykes L, Quan H. The impact of the electronic medical record on structure, process, and outcomes within primary care: a systematic review of the evidence. J Am Med Inform Assoc 2011;18(6):732-7.

67. Moja L, Kwag KH, Lytras T, Bertizzolo L, Brandt L, Pecoraro V et al. Effectiveness of computerized decision support systems linked to electronic health records: a systematic review and meta-analysis. Am J Public Health 2014;104(12):e12-22.

68. Ammenwerth E, Schnell-Inderst P, Machan C, Siebert U. The effect of electronic prescribing on medication errors and adverse drug events: a systematic review. J Am Med Inform Assoc 2008;15(5):585-600.

\section{Correspondence to:}

Alexander Hörbst

Research Division eHealth and Telemedicine

University for Health Sciences, Medical Informatics, and Technology (UMIT)

Eduard-Wallnoefer-Zentrum 1

$6060 \mathrm{Hall}$ in Tirol, Austria

Tel.: + 435086483814

Fax: +43508648673814

E-mail: alexander.hoerbst@umit.at

Web: http://ehealth.umit.at 